\title{
Research on the Application of Big Data Mining in the Construction of Smart Campus
}

\author{
Xianmin Zhang1,2, Jiajia Shen1, Peijian $\mathrm{Wu}^{1}$, Deliang Sun ${ }^{1}$ \\ ${ }^{1}$ School of Business Administration, Anhui University of Finance and Economics, Bengbu, China \\ ${ }^{2}$ University of Perpetural Help System Dalta, Alabang Zapote Rd., Pamplona Las Pinas City, Philippines \\ Email: zxm1256@qq.com
}

How to cite this paper: Zhang, X.M., Shen, J.J., Wu, P.J. and Sun, D.L. (2021) Research on the Application of Big Data Mining in the Construction of Smart Campus. Open Access Library Journal, 8: e8169. https://doi.org/10.4236/oalib.1108169

Received: November 8, 2021

Accepted: November 20, 2021

Published: November 23, 2021

Copyright $\odot 2021$ by author(s) and Open Access Library Inc.

This work is licensed under the Creative Commons Attribution International License (CC BY 4.0).

http://creativecommons.org/licenses/by/4.0/

(c) (i) Open Access

\begin{abstract}
With the development of science and technology, the informatization construction of colleges and universities has stepped into the era of big data, and the informatization construction of colleges and universities has changed from digital campus to smart campus. This paper first summarizes the research status from the concept and evolution of the smart campus, the meaning and application of big data and data mining, the characteristics and architecture of the construction of the smart campus, and then puts forward the common problems in the construction of the smart campus. Finally it is concluded that increase knowledge, cultivate awareness of data sharing, and establish evaluation system improvement strategy in order to provide reference for the construction of wisdom campus in colleges and universities.
\end{abstract}

\section{Subject Areas}

Big Data Search and Mining, Educational Psychology

\section{Keywords}

Dig Data, Smart Campus, Educational Informationization

\section{Introduction}

In 2010, in the 12th Five-Year Plan of informatization, Zhejiang University proposed to build an "exciting" "smart campus", a safe, stable, environmentally friendly and energy-saving campus. With the continuous enhancement of China's economic strength and scientific and technological level, the development of digital technology has entered a new stage and gradually penetrated into the application of smart campus in colleges and universities, and the intelligent, information-based and scientific campus management has been significantly im- 
proved. The construction of smart campus involves big data, 5G, cloud computing, artificial intelligence, Internet of Things, mobile Internet and other emerging technologies, which bring new experience to work, study and life on smart campus [1]. Under the background of big data-driven era, it is an inevitable trend of development to shift from the construction of digital campus to the construction of smart campus, and it also provides the possibility for the realization of the promotion and construction of smart campus. The construction of smart campus is also a practical example of the successful application of big data technology.

Previous studies mainly focused on the system framework of the construction of smart campus. Xing Xuehua (2020) pointed out that smart campus is a digital ecosystem integrating teaching, scientific research, management and campus life, and proposed the construction path of smart campus and pan-campus network in the 5G era [2]. Zhang Jue (2019) points out that the application of advanced science and technology promotes the construction and development of smart campus, among which the application of data processing technology plays a key role [3]. According to the General Framework of Smart Campus released by the State, Wu Xihua (2020) adopts the architecture deployment of "cloud computing + big data technology" to build a smart campus system architecture of "two systems + four integration" [4]. Ma Dongbo (2020) pointed out that the key technologies of data analysis and processing in the process of smart campus construction include campus network system construction, click traffic statistics, one-card system, campus Internet monitoring equipment, campus two-dimensional code mini program, etc. [5]

At present, due to the lack of practice in the construction of smart campuses, it is more confused about how to transition from digital campuses [6]. Based on the above research and analysis, this paper intends to answer the following questions, such as whether the understanding of smart campus is sufficient, whether the data processing and integration are mature enough, and how to judge the realization and perfection of promoting and constructing smart campus? The integration of technologies such as IoT, cloud computing, and big data, provides the basis of emerging technologies that helps to generate new management methods or improve existing ones [7]. This paper discusses the construction of smart campus from the perspective of data mining and puts forward some problems and countermeasures.

\section{Research Status}

\subsection{Concept and Evolution of Smart Campus}

With the in-depth application of big data and other emerging digital technologies in the construction of smart campus in colleges and universities, the study, life and work of colleges and universities have undergone qualitative changes and reached a new level, ushering in new development of management [1]. In June 2018, the State Administration for Market Regulation and Standardization 
Administration of China released the standard document "General Framework of Smart Campus", indicating that smart campus refers to the organic connection between physical space and information space, so that anyone, anytime, anywhere can conveniently access resources and services. Xing Xuehua (2020) points out that smart campus means that all campus businesses (including classroom teaching, education and scientific research, teaching management, campus life management, etc.) realize informatization and intelligentization [2]. Lu Jinmei (2020) points out that smart campus is a variety of comprehensive information service platforms that can provide personalized services for teachers and students and build a new campus model integrating management, teaching, life and scientific research [8]. The existing concept of smart campus usually refers to an intelligent integrated environment of campus work, study and life based on the Internet of things and supported by various application service systems. Its prominent feature is the full integration of teaching, scientific research, management and campus life.

It is worth noting that although smart campus and digital campus are both for the realization of information management, there are great differences in meaning, characteristics, technical means and implementation methods. "Smart campus" is evolved on the basis of "digital campus", is the performance of digital campus upgrade to a certain stage, is a stage of the development of digital campus. As "campus digitization" moves toward "campus wisdom", "wisdom", "intelligence", "big data" and "big sharing" will be the key words for the development of college information education in the future [4]. Digital campus is based on the interconnectivity between people on the basis of the Internet, while smart campus is to achieve information exchange through the Internet of things, and expand the scope to people and things, things and things, truly intelligent.

\subsection{Features of Big Data and Functions of Data Platform}

Big data is a virtualization technology that uses distributed computer structure to mine massive data. It is characterized by four aspects: large data volume, multiple types, value emergence and high efficiency. As an emerging digital technology and management mode in IT field, big data has important implications and reference value for intelligent and scientific decision-making. Attaching importance to and making full use of big data technology and grasping key links such as data collection, analysis and processing can effectively promote the speed and height of the construction of smart campus [5].

In the construction of smart campus, data is the most important element, which is also one of the innovations of smart campus. As an independent and important asset, data should be comprehensively collected (perceived), orderly transferred and unified in structure. Only through aggregation and analysis can its intrinsic value be reflected and value can be continuously generated. In addition, in the construction of smart campus, the supporting role of big data platform is particularly important, which should be equipped with information col- 
lection, data storage, data analysis and processing, data exchange and sharing and other functions. The construction of big data platform covers two parts: infrastructure and application support. It is the aggregation center of all data on campus and the core of smart campus data processing.

\subsection{The Difference between Data Mining and Data Analysis}

Big data refers to the collection of data that cannot be captured, managed and processed by conventional software tools in an affordable time range. It is a massive, high-growth and diversified information asset that requires new processing modes to have stronger decision-making power, insight and discovery ability and process optimization ability. The key of big data technology is to mine valuable information for users from massive data, rather than simply improve hardware and software facilities.

Data analysis refers to a process in which a large number of collected data are analyzed with appropriate statistical analysis methods, useful information is extracted and conclusions are formed, and data are studied and summarized in detail. This process is also supported by the quality management system, and data analysis helps people make judgments so that appropriate actions can be taken.

Data mining is also called data exploration and data mining. It is a step in database knowledge discovery, which generally refers to the process of searching hidden information from a large amount of data through algorithms. Data mining is usually associated with computer science, and is achieved through statistics, online analytical processing, information retrieval, machine learning, expert systems and pattern recognition.

The conclusion of data analysis is the result of human intellectual activity, while the conclusion of data mining is the knowledge rule discovered by machine from the learning set, training set or sample set. Big data needs to analyze trends and development, while data mining mainly discovers problems and diagnoses.

\subsection{Characteristics and Approaches of Smart Campus Construction}

Compared with digital campus, the core feature of smart campus is that it obtains massive activity process and status data through various intelligent terminals, perceptive devices and information systems, and grasps the rules of things based on these massive data analysis to carry out intelligent application. He Houhua (2020) believes that the characteristics of smart campus construction in colleges and universities are reflected in the four aspects of mutual integration with external wisdom, intelligent integration of business applications, promotion and application of mobile intelligent terminals, and the rapid development of the Internet [9]. Nanjing University of Posts and Telecommunications points out in its smart campus construction plan that its core characteristics are reflected in three 
aspects: providing personalized services for students through intelligent sensing environment and platform, integrating into various service fields of the school, and communicating with the outside world and sensing. The construction of intelligent campus information platform can not only share information resources in a certain area, but also carry out intelligent management according to the environment and user characteristics and provide users with exclusive customized services [10]. Therefore the construction of campus network should pay attention to the construction of the Internet, provide a stable, reliable and safe network environment, and plan the hardware and software system.

Relying on the scientific concept of campus construction and development, the promotion and construction of smart campus can be promoted through the use of advanced cutting-edge information technology, so as to create a comprehensive campus service environment, realize one-stop service, and comprehensively improve the ability of scientific research, management service, talent training and other aspects [11]. At the same time, the use of big data modeling thinking in the construction and promotion of smart campus at the college level can also make the campus information and data dynamic management, intelligent management.

\subsection{Architecture of Smart Campus Construction System}

Many scholars have also studied the system architecture of smart campus. Wu Xihua (2020) takes "cloud computing + big data technology" as an example and proposes to build a smart campus system architecture of "two systems + four integration". As illustrated in Figure 1, the two systems refer to the standard evaluation system and the security guarantee system, and the four fusion refers to the application fusion layer, service fusion layer, data fusion layer and network fusion layer [4]. Yang Min (2020) studied Sun Yat-sen University's bottom-up construction of data center system architecture and the practice of data hierarchical system design and construction of global data. It can be proved that data computing efficiency and accuracy are improved when data center is used to build a global data hierarchical standard system to provide data services. This can well meet the requirements of business departments to obtain analysis results quickly and accurately [12].

\section{Problems Existing in the Construction of Smart Campus}

According to previous research, the work of smart campus in China has achieved some results, teaching and research, study life and other daily work have been significantly improved. However, it is still in the initial stage and there are still many problems to be solved in the construction process. First of all, although some scholars have studied the concept of smart campus, their understanding of smart campus is not enough. Secondly, through research and analysis, the volume of big data is large and there are many types of big data, so there are problems such as incomplete data processing technology and inefficient data 


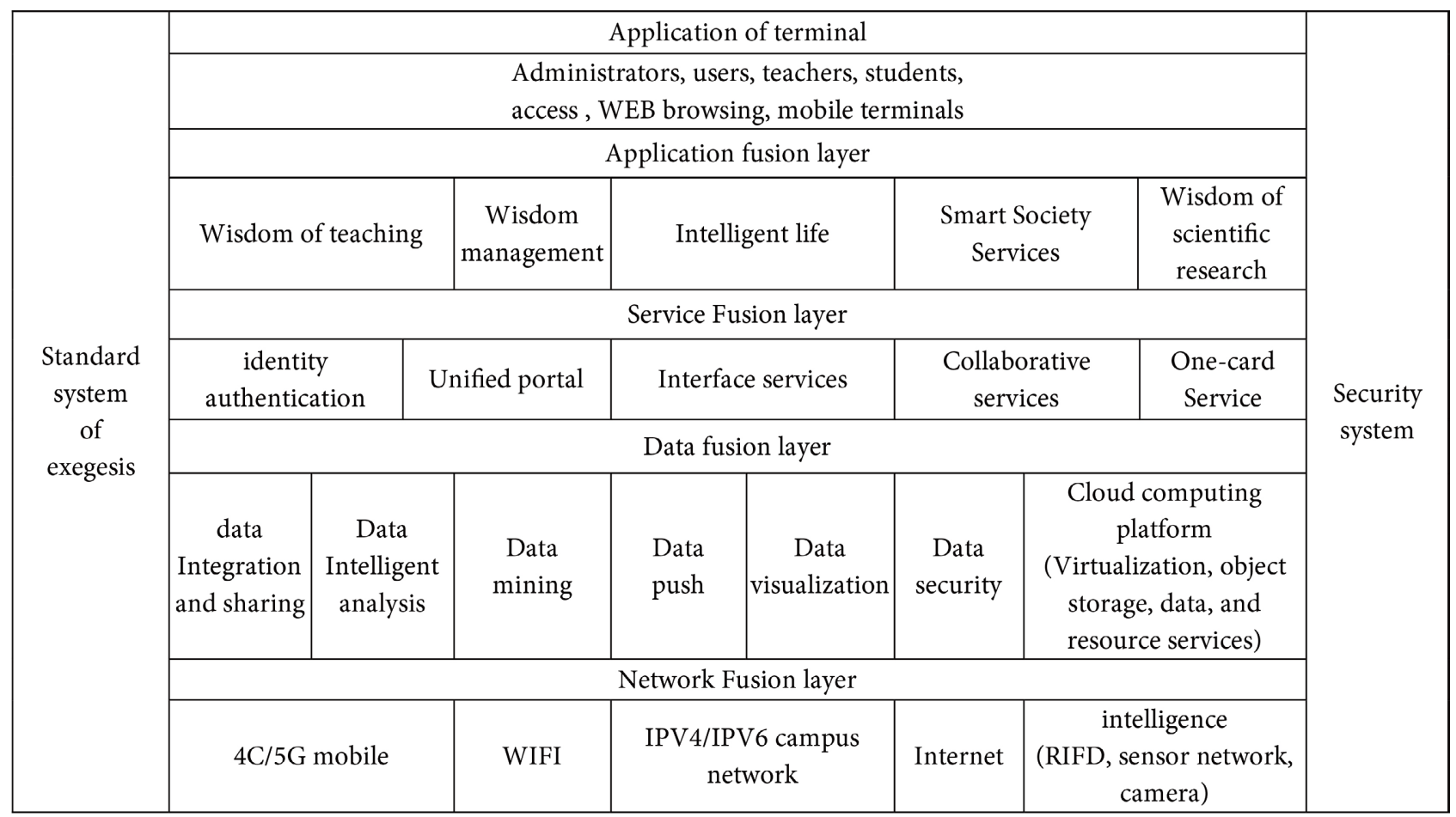

Figure 1. Architecture of smart campus system.

fusion. Finally, although some existing studies have constructed a smart campus system, a unified and perfect index evaluation system is yet to be established.

\subsection{Insufficient Understanding of Smart Campus}

In the context of big data-driven era, the construction of smart campus has become an inevitable trend. Although colleges and universities across the country are trying to build a comprehensive information smart campus, the understanding of smart campus is not thorough enough, resulting in a series of disharmony between the actual construction process and the preset plan. The construction of smart campus only stays on the surface, and does not get rid of the bondage of digital campus, so it fails to build a real sense of smart campus. The fundamental purpose of the construction of smart campus is to facilitate teachers and students, realize the interconnection between human, equipment, nature and social factors, so that teachers and students can experience intelligence and convenience in teaching, learning, life and other aspects, and build a flexible and efficient campus system. In terms of the top-level design, the user needs of teachers and students are not met, and the lack of attention to the subject needs affects the sense of user experience and increases the burden of teachers and students, which runs counter to the original goal of convenience. In addition, due to the lack of knowledge, some colleges and universities lack experience and sufficient reference examples to make reasonable planning of hardware and software facilities arrangement, and excessive accumulation of hardware facilities leads to waste of resources. 


\subsection{Data Processing and Fusion Are Not Mature Enough}

The work of data collection and analysis in colleges and universities is huge and complicated. The sum of the simple actions of each individual in the school produces a huge amount of data. Every seemingly insignificant behavior of students, such as tuition payment, examination registration fee payment, canteen consumption, online chatting, and examination result entry, will affect the statistical work of big data. The existing data collection and processing technology is not perfect, and the advanced data processing software is not completely popularized to every university administrator, which brings great inconvenience to the data processing work.

Mass data is the basis of big data. The big data in the campus comes from various functional departments. Influenced by the traditional model, a large amount of data is distributed in various independent functional departments, and there is a lack of awareness of data sharing among departments. One of the most important problems faced by universities in big data is data fusion. Without data fusion, the potential value of data cannot be brought into full play.

\subsection{The Evaluation Index System Needs to Be Improved}

How to judge whether the goal of promoting and building a smart campus has been achieved? How to evaluate the perfection of promotion and construction? This is a problem that must be considered during the construction of smart campus. Existing researches mostly focus on the concept, system and mechanism, path, mode and policy of smart campus, while ignoring the index system reflecting the construction achievements. We must establish a unified and reasonable index measurement system while continuously promoting the intelligent construction. Whether the index system is perfect or not directly affects the construction process of smart campus. Only by constructing the index system of modern universities can we further promote the quality of education and teaching and the seamless connection between talents and social needs [8].

\section{Smart Campus Construction Strategy}

Previous studies have mentioned that although many colleges and universities try to build smart campuses, their understanding of smart campuses is not thorough, and the management of some colleges and universities has not reached a consensus on the construction of smart campuses [9]. This paper puts forward that we should pay attention to the construction of smart campus ideologically, and gives some ways to improve our understanding. The complexity of data of teachers and students in colleges and universities has been analyzed before, and some colleges and universities still use the original teaching management and information search methods [9]. This work gives suggestions on data processing and fusion. At the same time, most of the previous studies analyzed how to construct, manage and establish a data system for smart campus, but few involved in the evaluation after construction. This analysis focuses on how to establish an 
evaluation index system and puts forward countermeasures and suggestions.

\subsection{Improve the Understanding of Smart Campus}

Promoting the construction of education informatization is a response to social development and also conforms to the trend of the development of The Times. To solve the problem of insufficient understanding of smart campus, we need to pay attention to the development of educational informatization and setting up the concept of correct and intelligent campus are the foundation for the establishment of comprehensive informatization and scientization. To enhance our understanding, we can start from the following aspects: first, correctly distinguish the meaning of smart campus and digital campus, try to get rid of the shackles of digital campus, and put the innovation of wisdom into practice; The second is to truly start from the needs of users, to solve practical problems; The third is to strengthen the core change of the transmission of educational thought, and to truly understand the purpose of educational informatization is to build a bridge for the construction of smart campus and smart education.

\subsection{Cultivate Awareness of Data Sharing}

Information resources can give full play to their maximum value only on the premise of mutual flow and scale effect. In the construction of smart campus, data sharing awareness among departments should be strengthened under the condition of ensuring data security and clear operation authority, so as to solve the problem of immature data processing and fusion. In the construction of big data platform in smart campus, it is necessary to completely break through data islands and fully integrate various businesses. In the implementation process, if there is no unified plan and no long-term goal, different business departments will adopt different databases for data, which will bring great difficulty to data sharing and fusion, and even form information islands, turning big data into "garbage data". Effective data fusion is a prerequisite for the formation of highquality big data.

\subsection{Establish an Evaluation System}

The current evaluation system needs to be improved. Only by establishing the evaluation system can we give feedback to the construction situation, and then cause attention to the problem and lead the right direction. The construction of index system should follow some principles: First, the index design should have the understandability, comparability, relevance and importance, must be based on the different development of colleges and universities during the same period and in different periods of their development in comparative analysis found the problems existing in the process of construction and the insufficiency, and promptly take effective control measures to correct deviation, achieve the development goals. Second, the index system should be hierarchical, which can reflect the differences between different evaluation objects. Third, the index system 
should be streamlined and powerful, In this way, the index that can best reflect the meaning of smart campus should be selected from numerous relevant indicators, instead of blindly pursuing the complexity of the calculation of increasing the number. Fourthly, data indicators should comprehensively reflect the availability of data sources, data fusion and sharing, and the persistence of data analysis.

\section{Conclusion}

Big data such as the development of digital technology brings new opportunity to the wisdom campus construction, large data mining will provide the source of data for wisdom campus construction services, and modeling of large data organization, is the key to dig up data values. The organic combination of two aspects can help to campus network management, student life, teaching and other aspects of efficient integration. Building a smart campus with comprehensive information is also in line with the development trend of education informatization, but there are still a series of problems to be solved in the process of construction. Only by strengthening technical means and ideological awareness can the smart campus be comprehensively improved.

\section{Fund Project}

Education Development research project of Anhui University of Finance and Economics, Research on the application of big data mining in the construction of smart campus (No. 2019YB015).

\section{Conflicts of Interest}

The authors declare no conflicts of interest.

\section{References}

[1] Qin, D., Li, L.X. and Li, L.L. (2020) Privacy Risk Analysis and Protection Strategy of College Smart Campus Students in the Era of Big Data. Network Security Technology and Application, 11, 110-112.

[2] Xing, X.H. (2020) Construction and Application of Smart Campus and Pan-Campus Network in 5G Era. Computer Knowledge and Technology, 16, 172-173.

[3] Zhang, J. (2019) Application Analysis of Data Processing Technology in the Construction of Smart Campus. Value Engineering, 38, 270-272.

[4] Wu, X.H. (2020) Research on Architecture Design of Intelligent Construction System of Higher Vocational Campus Based on Big Data. Information and Computer (Theory Edition), 32, 174-176.

[5] Ma, D.B. (2020) Application and Prospect of Big Data Technology in Smart Campus. Industry \& Technology Forum, 19, 45-46.

[6] Villegas-Ch, W., Molina-Enriquez, J., Chicaiza-Tamayo, C., et al. (2019) Application of a Big Data Framework for Data Monitoring on a Smart Campus. Sustainability, 11, Article No. 5552. https://doi.org/10.3390/su11205552

[7] Li, W.G. (2021) Design of Smart Campus Management System Based on Internet of Things Technology. Journal of Intelligent \& Fuzzy Systems, 40, 3159-3168. 
https://doi.org/10.3233/JIFS-189354

[8] Lu, J.M. (2020) Practical Research on the Construction of Smart Campus in Universities in the Era of Big Data. Higher Education Journal, 32, 153-156.

[9] He, H.H. (2020) Discussion on the Construction of Smart Campus in Universities under the Background of Big Data. Information \& Computer (Theory Edition), 32, 228-230.

[10] Wang, S.Y. (2020) Construction of Intelligent Campus Informatization Operation Support Platform. Information Communication, 10, 139-141.

[11] Chen, X. (2020) An Effective Way to Promote University Management and Education in the Era of Big Data. Public Standardization, 21, 250-252.

[12] Yang, M., He, H.T. and Zhang, Y.Q. (2020) Design and Construction of Campus Data System Based on Data Center. Journal of Shenzhen University of Science and Technology, 37, 95-100. 